\title{
PELAKSANAAN PENINGKATAN HAK GUNA BANGUNAN MENJADI HAK MILIK UNTUK RUMAH TINGGAL DI KANTOR PERTANAHAN KARAWANG DITINJAU DARI KEPUTUSAN MENTERI NEGARA AGRARIA / KEPALA BADAN PERTANAHAN NASIONAL NOMOR 6 TAHUN 1998 TENTANG PEMBERIAN HAK MILIK ATAS TANAH UNTUK RUMAH TINGGAL
}

\author{
Irma Garwan, S.H., M.H Email : irma.garwan@ubpkarawang.ac.id \\ Zarisnov Arafat, S.H., M.H Email : zarisnov@ubpkarawang.ac.id \\ Yola Ardila, S.H Email : YolaArdila@mhs.ubpkarawang.ac.id \\ Fakultas Hukum Universitas Buana Perjuangan Karawang
}

\begin{abstract}
ABSTRAK
Tanah merupakan faktor yang sangat penting dalam kehidupan masyarakat. Selain sandang dan pangan, manusia juga membutuhkan tanah sebagai tempat tinggal mereka. Untuk memberikan kepastian hukum dan menjamin kepemilikan tanah kepada pemegang hak atas tanah, maka mereka harus mempunyai bukti yang disebut sertipikat. Bahwa rumah tinggal diperlukan masyarakat, maka tanah digunakan sebagai rumah tinggal dari status Hak Guna Bangunan menjadi Hak Milik untuk rumah tinggal. Masalah yang dikaji dalam penelitian ini adalah bagaimana pelaksanaan peningkatan Hak Guna Bangunan menjadi Hak Milik untuk rumah tinggal di Kantor Pertanahan Kabupaten Karawang? dan apa saja syarat-syarat yang harus dipenuhi dalam pendaftaran peningkatan Hak Guna Bangunan menjadi Hak Milik untuk rumah tinggal?. Berkaitan dengan masalah tersebut, penelitian ini bertujuan untuk mengetahui pelaksanaan peningkatan Hak Guna Bangunan menjadi Hak Milik untuk rumah tinggal di Kantor Pertanahan Kabupaten Karawang. Metode pendekatan yang digunakan dalam penelitian ini adalah Yuridis empiris yaitu pendekatan yang menitik beratkan pada pengumpulan data dari studi lapangan sebagai data utama dan studi kepustakaan sebagai data pelengkap. Adapun hipotesa dari penulis adalah perihal pelaksanaan Peningkatan Hak Guna Bangunan menjadi Hak Milik adalah sering ditemuinya pemohon yang mendaftarkan peningkatan dengan berkas yang kurang lengkap dikarenakan kurangnya pengetahuan terkait proses tersebut sehingga menunda proses peningkatan hak dan membutuhkan waktu yang lama.
\end{abstract}

Kata Kunci : Peningkatan Hak, Hak Guna Bangunan, Hak Milik 


\section{ABSTRACT}

Land is a very important factor in people's lives. In addition to clothing and food, humans also need land as their residence. To provide legal certainty and guarantee ownership of land to holders of land rights, they must have evidence called certificates. Whereas a residence is needed by the community, the land is used as a residence from the status of Building Use Rights to become Ownership Rights for the residence. The problem examined in this study is how to implement an increase in Building Use Rights to Property Rights for residences in the Karawang Regency Land Office? and what are the conditions that must be met in registering an increase in the Right to Build into Ownership Rights for residences? In connection with these problems, this study aims to determine the implementation of the increase in Building Use Rights to Property Rights for residences in the Karawang Regency Land Office. The method of approach used in this study is empirical juridical, which is an approach that focuses on collecting data from field studies as the main data and library studies as supplementary data. The hypothesis of the author is that regarding the implementation of the Improvement of Building Rights to Ownership Rights, it is often the case that an applicant registers an increase with an incomplete file due to lack of knowledge related to the process, thus delaying the process of increasing rights and takes a long time.

\section{Keywords: Increased Rights, Building Rights, Ownership Rights}


PELAKSANAAN PENINGKATAN HAK GUNA BANGUNAN MENJADI HAK MILIK UNTUK RUMAH TINGGAL DI KANTOR PERTANAHAN KARAWANG DITINJAU DARI KEPUTUSAN MENTERI NEGARA AGRARIA / KEPALA BADAN PERTANAHAN NASIONAL NOMOR 6 TAHUN 1998 TENTANG PEMBERIAN HAK MILIK ATAS TANAH UNTUK RUMAH TINGGAL: Irma Garwan, Zarisnov Arafat, Yola Ardila

\section{PENDAHULUAN}

Tanah merupakan faktor yang sangat penting dalam kehidupan suatu masyarakat, terlebih-lebih di lingkungan masyarakat Indonesia yang sebagian besar penduduknya menggantungkan kehidupannya dari tanah. Dalam rangka pembangunan Nasional untuk mewujudkan masyarakat yang adil dan makmur berdasarkan Pancasila dan Undang-Undang Dasar Negara Republik Indonesia 1945 (selanjutnya disebut UUDNRI 1945). ${ }^{1}$ Selain itu, tanah juga sebagai modal utama baik sebagai wadah pelaksanaan pembangunan maupun sebagai faktor produksi untuk menghasilkan komoditas-komoditas perdagangan guna meningkatkan Pendapatan Nasional.

Pengertian tanah diatur dalam Pasal 4 Undang-Undang Nomor 5 Tahun 1960 Tentang Peraturan Dasar Pokok-Pokok Agraria dinyatakan sebagai berikut:

"Atas dasar hak menguasai dari negara sebagai yang dimaksud dalam Pasal 2 ditentukan adanya macam-macam hak atas permukaan bumi, yang disebut tanah, yang

1 Undang-Undang Dasar Negara Republik Indonesia 1945] dapat diberikan kepada dan dipunyai oleh orang-orang, baik sendiri maupun bersama-sama dengan orang lain serta badanbadan hukum" 2

Yang dimaksud istilah tanah dalam Pasal di atas ialah permukaan bumi. Makna permukaan bumi sebagai bagian dari tanah yang dapat di haki oleh setiap orang atau badan hukum. ${ }^{3}$

Seluruh bumi, air dan ruang angkasa, termasuk kekayaan alam yang terkandung didalamnya dalam wilayah Republik Indonesia, sebagai karunia Tuhan Yang Maha Esa adalah bumi, air dan ruang angkasa bangsa Indonesia dan merupakan kekayaan nasional sebagaimana diatur dalam Pasal 1 Angka (2) Undang-Undang Republik Indonesia Nomor 5 Tahun 1960 Tentang Peraturan Dasar Pokok-Pokok Agraria. ${ }^{4}$

2 Pasal 4 Undang-Undang Nomor 5 Tahun 1960 Tentang Peraturan Dasar Pokok-Pokok Agraria

3 Supriadi, Hukum Agraria, Sinar Grafika, Jakarta, 2015, hlm 3

4 Pasal 1 Ayat (2) Undang-Undang Republik Indonesia Nomor 5 Tahun 1960 Tentang Peraturan Dasar Pokok-Pokok Agraria 
PELAKSANAAN PENINGKATAN HAK GUNA BANGUNAN MENJADI HAK MILIK UNTUK RUMAH TINGGAL DI KANTOR PERTANAHAN KARAWANG DITINJAU DARI KEPUTUSAN MENTERI NEGARA AGRARIA / KEPALA BADAN PERTANAHAN NASIONAL NOMOR 6 TAHUN 1998 TENTANG PEMBERIAN HAK MILIK ATAS TANAH UNTUK RUMAH TINGGAL: Irma Garwan, Zarisnov Arafat, Yola Ardila

Hal tersebut sesuai dengan amanah Pasal 33 Undang-Undang Dasar Negara Republik Indonesia 1945.

Pelaksanaan hukum agraria didasarkan atas kebijaksanaan baru dengan memakai tafsir yang baru pula sesuai dengan jiwa Pancasila dan Pasal 33 Ayat (3) Undang-Undang Dasar Negara Republik Indonesia 1945. ${ }^{5}$

Tanah sebagai sumber daya agraria adalah yang paling banyak dimanfaatkan oleh manusia. Selain itu Peraturan Perundang-Undangan mengenai tanah adalah yang paling banyak dibandingkan peraturan sumber daya agraria lainnya. ${ }^{6}$

Selain sandang dan pangan, manusia juga membutuhkan tanah, karena sejak manusia di ciptakan oleh Tuhan Yang Maha Esa, tanah banyak dibutuhkan manusia sebagai tempat tinggal. Tanah sangatlah penting bagi kehidupan manusia, dan dalam hal ini pemerintah juga mempunyai UndangUndang yang mengatur tentang

\footnotetext{
5 Bernhard limbong, Hukum Agraria Nasional, Pustaka Margaretha, Jakarta, 2012, hlm 199.

6 Waskito dan Hadi Arnowo, Pertanahan, Agraria, dan Tata Ruang, Kencana Pranadamedia Group, Jakarta, 2017, hlm 5.
}

pertanahan. Karena akibat dari mahalnya harga tanah dan biaya pengurusan suratsurat hak kepemilikan tanah atau sertipikat hak milik sebagai tempat tinggal, selain itu dikarenakan kesadarah hukum masyarakat masih kurang terhadap pengurusan peningkatan hak milik atas tanah. Tanah merupakan sarana utama dari lingkungan alam yang memberikan arti fungsional bagi masyarakat, terutama untuk rumah sebagai tempat tinggal manusia. Dalam realitasnya, masih banyak pemilik tanah yang belum memiliki sertipikat hak milik tanah sebagai tanda bukti kepemilikan hak milik atas tanahnya.

Hak Guna Bangunan (selanjutnya disebut HGB) adalah kewenangan yang diberikan oleh pemerintah atau suatu hak yang didapatkan untuk menggunakan sebuah lahan yang bukan miliknya sendiri dengan jangka waktu 30 tahun yang atas permintaan pemegang hak mengikat keperluan serta keadaan bangunan-bangunannya dan dapat diperpanjang kembali sampai dengan jangka waktu maksimum 20 tahun. $^{7}$

7 Peraturan Pemerintah Republik Indonesia Nomor 40 Tahun 1996 Tentang Hak Guna 
PELAKSANAAN PENINGKATAN HAK GUNA BANGUNAN MENJADI HAK MILIK UNTUK RUMAH TINGGAL DI KANTOR PERTANAHAN KARAWANG DITINJAU DARI KEPUTUSAN MENTERI NEGARA AGRARIA / KEPALA BADAN PERTANAHAN NASIONAL NOMOR 6 TAHUN 1998 TENTANG PEMBERIAN HAK MILIK ATAS TANAH UNTUK RUMAH TINGGAL: Irma Garwan, Zarisnov Arafat, Yola Ardila

Sertipikat Hak Milik (selanjutnya disebut SHM) adalah jenis sertifikat yang pemegangnya memiliki kekuasaan penuh sebagai pemilik dari lahan di sebuah kawasan dengan luas tertentu yang tercantum dalam surat dengan waktu yang tidak terbatas. Dengan demikian, pemegang sertipikat yang tercantum dalam surat menjadi pemilik seutuhnya tanpa adanya campur tangan dan kemungkinan kepemilikan bagi pihak lain.

Perbedaan Sertipikat Hak Milik dan Sertipikat Hak Guna Bangunan dapat dilihat dari tingkat kuasa dan jangka waktu kepemilikannya. Sertipikat Hak Milik dapat diwariskan dan tidak memiliki batasan waktu kepemilikan sedangkan sertipikat Hak Guna Bangunan memiliki batasan waktu dan diperkenankan untuk diperpanjang masa penggunaannya. Sertipikat Hak Milik bisa digunakan untuk jaminan kepada lembaga keuangan jika ingin mengajukan kredit hal ini berbeda jika hanya memiliki sertipikat Hak Guna Bangunan. Oleh karena itu, bila bertekad

Usaha, Hak Guna Bangunan dan Hak Pakai Atas Tanah untuk menetap di bangunan dan tanah dalam jangka waktu lama atau berencana untuk investasi jangka panjang, sebaiknya membeli properti yang berstatus Sertipikat Hak Milik. ${ }^{8}$

Hak guna bangunan memiliki kekuatan hukum yang lebih rendah dari hak milik. Hak guna bangunan memiliki keterbatasan dalam jangka waktu yang pada suatu saat akan berakhir. Hal ini terkandung dalam Pasal 35 Ayat (1) dan (2) UndangUndang Republik Indonesia Nomor 5 Tahun 1960 Tentang Peraturan Dasar Pokok-Pokok Agraria (untuk selanjutnya disebut UUPA), sehingga para pemegang sertipikat Hak Guna Bangunan harus memperpanjang lagi jangka waktunya, namun hal tersebut kurang efisien karena prosesnya yang panjang dan lama dengan biaya yang terhitung tidak sedikit. ${ }^{9}$

Berbeda dengan hak milik yang mempunyai sifat turun-temurun, terkuat, terpenuh, serta memiliki

\footnotetext{
8 https://www.lamudi.co.id/journal/perbedaanhak-guna-bangunan-dengan-hak-milik/

${ }^{9}$ Pasal 35 Ayat (1) dan (2) Undang-Undang Republik Indonesia Nomor 5 Tahun 1960 Tentang Peraturan Dasar Pokok-Pokok Agraria
} 
PELAKSANAAN PENINGKATAN HAK GUNA BANGUNAN MENJADI HAK MILIK UNTUK RUMAH TINGGAL DI KANTOR PERTANAHAN KARAWANG DITINJAU DARI KEPUTUSAN MENTERI NEGARA AGRARIA / KEPALA BADAN PERTANAHAN NASIONAL NOMOR 6 TAHUN 1998 TENTANG PEMBERIAN HAK MILIK ATAS TANAH UNTUK RUMAH TINGGAL: Irma Garwan, Zarisnov Arafat, Yola Ardila

kekuatan hukum yang lebih tinggi dibanding dengan hak guna bangunan, sehingga pemegang hak milik sudah tidak perlu lagi memperpanjang jangka waktu hak atas tanahnya. Meningkatnya kebutuhan masyarakat menyebabkan para pemegang hak guna bangunan merasa perlu untuk meningkatkan status hak atas tanahnya menjadi hak milik, terutama atas tanah untuk rumah tinggal. Kebutuhan masyarakat yang terus meningkat tersebut dapat mempengaruhi pola pikir masyarakat, terutama bagi masyarakat yang memiliki tanah yang masih berstatus hak guna bangunan. Apabila jangka waktu hak atas tanahnya sudah berakhir atau bahkan yang belum berakhirpun, mereka memilih segera mengajukan permohonan untuk meningkatkan status hak atas tanahnya menjadi hak milik dibanding hanya melakukan perpanjangan jangka waktu hak guna bangunannya.

Merujuk pada ketentuan yuridis yang ada yaitu Keputusan Menteri Negara Agraria / Kepala Badan Pertanahan Nasional Nomor 6 Tahun 1998 Tentang Pemberian Hak Milik atas tanah untuk rumah tinggal merupakan dasar hukum yang dijadikan patokan bagi pemohon dalam upaya hukum mengajukan perubahan status hak atas tanah dari Hak Guna Bangunan menjadi Hak Milik. Hal ini tentunya menuntut pemahaman yang benar mengenai macam-macam hak atas tanah yang diharapkan pemohon dapat mengurangi kesalahpahaman yang dapat meresahkan pemegang hak atas tanah.

Dengan demikian, berdasarkan pada hal-hal di atas bahwa aturan dapat menjadi landasan yuridis dilakukannya upaya hukum peningkatan Hak Guna Bangunan menjadi Hak Milik dalam penerapannya belum sepenuhnya sesuai dikarenakan masih ada beberapa kendala/hambatan yang timbul di dalamnya, sehingga mengakibatkan apabila tidak merubah status tanah dari Hak Guna Bangunan menjadi Hak Milik, maka pemilik rumah hanya akan memiliki bangunan/rumahnya saja tanpa memiliki tanah tersebut.

Apabila tanah sudah mereka dapatkan, manusia akan mempertahankan tanah tersebut sebagai kekayaan turun temurun. Keputusan 
PELAKSANAAN PENINGKATAN HAK GUNA BANGUNAN MENJADI HAK MILIK UNTUK RUMAH TINGGAL DI KANTOR PERTANAHAN KARAWANG DITINJAU DARI KEPUTUSAN MENTERI NEGARA AGRARIA / KEPALA BADAN PERTANAHAN NASIONAL NOMOR 6 TAHUN 1998 TENTANG PEMBERIAN HAK MILIK ATAS TANAH UNTUK RUMAH TINGGAL: Irma Garwan, Zarisnov Arafat, Yola Ardila

Menteri Negara Agraria / Kepala Badan

Pertanahan Nasional Nomor 6 Tahun 1998 Tentang Pemberian Hak Milik atas tanah untuk rumah tinggal menerangkan bahwa tanah sebagai tempat tinggal manusia dan dapat digunakan untuk hidup secara nyaman dan tentram tanpa ada gangguan apapun, asalkan berdasarkan Undang-Undang yang berlaku. ${ }^{10}$

Tanah sebagai dasar berpijaknya sebuah bangunan rumah untuk sarana tempat tinggal berperan sangat penting dalam kehidupan masyarakat. Persoalan hak atas tanah pada dasarnya berkaitan dengan status hukum seluruh bidang tanah yang akan dimohonkan haknya dan pengaturan mengenai status tanah tidak dapat dipisahkan dari eksistensinya di negara hukum.

Hubungan antara pemegang hak dengan tanah yang dihaki merupakan hubungan yang erat, yaitu untuk memungkinkan pemegang hak atas tanah menggunakan dan memakainya guna memenuhi suatu kebutuhan tertentu.

${ }^{10}$ Keputusan Menteri Negara Agraria / Kepala Badan Pertanahan Nasional Nomor 6 Tahun 1998 Tentang Pemberian Hak Milik atas tanah untuk rumah tinggal
Pemberian Hak Milik untuk rumah tinggal melalui proses peningkatan hak atas tanah adalah pemberian Hak Milik dari yang masih berstatus Hak Guna Bangunan.

Untuk memberikan kepastian hukum dan perlindungan hukum kepada pemegang hak atas tanah atau hak-hak lain yang terdaftar agar dengan mudah membuktikan bahwa dirinya sebagai pemegang hak atas tanah yang bersangkutan, pemegang Hak Guna Bangunan yang telah dijadikan Hak Milik untuk rumah tinggal mendapat sebuah sertipikat. Sertipikat diterbitkan untuk kepentingan pemegang hak yang bersangkutan dengan data fisik dan data yuridis tanah yang telah didaftarkan dalam buku tanah, dan diserahkan kepada pihak yang namanya tercantum dalam buku tanah yang bersangkutan sebagai pemegang hak atau kepada pihak lain yang dikuasakan olehnya.

Sehubungan dengan itu, berbagai jenis hak atas tanah menurut ketentuan Undang-Undang Nomor 5 Tahun 1960 Tentang Peraturan Dasar Pokok-Pokok Agraria (UUPA) adalah untuk memenuhi keperluan pemegang hak atas tanah dan 
PELAKSANAAN PENINGKATAN HAK GUNA BANGUNAN MENJADI HAK MILIK UNTUK RUMAH TINGGAL DI KANTOR PERTANAHAN KARAWANG DITINJAU DARI KEPUTUSAN MENTERI NEGARA AGRARIA / KEPALA BADAN PERTANAHAN NASIONAL NOMOR 6 TAHUN 1998 TENTANG PEMBERIAN HAK MILIK ATAS TANAH UNTUK RUMAH TINGGAL: Irma Garwan, Zarisnov Arafat, Yola Ardila

memberikan perubahan hak atas tanah yang sudah dipunyainya menjadi hak atas tanah jenis lainnya. ${ }^{11}$

Pada dasarnya perubahan hak atas tanah menjadi hak atas tanah lainnya terdiri dari pelepasan hak atas tanah semula yang dikuasai dengan penetapan pemberian hak atas tanah yang baru. Kepada masyarakat yang akan melaksanakan harus berdasarkan Keputusan Menteri Negara Agraria / Kepala Badan Pertanahan Nasional Nomor 6 Tahun 1998 Tentang Pemberian Hak Milik atas tanah untuk rumah tinggal yang harus memenuhi syarat peningkatan hak atas tanahnya yaitu mempunyai surat Izin Mendirikan Bangunan (IMB) dan sertipikat Hak Guna Bangunan yang asli diserahkan kepada Kantor Pertanahan. ${ }^{12}$

Salah satu tujuan pendaftaran tanah sebagaimana ditetapkan dalam Pasal 3 Peraturan Pemerintah Nomor 24 Tahun 1997 Tentang Pendaftaran Tanah

11 R.Subekti, Tjitrosudibio.R, Kitab UndangUndang Hukum Perdata, Balai Pustaka, hlm 513.

12 Keputusan Menteri Negara Agraria / Kepala Badan Pertanahan Nasional Nomor 6 Tahun 1998 Tentang Pemberian Hak Milik atas tanah untuk rumah tinggal adalah untuk memberikan kepastian hukum dan perlindungan hukum kepada pemegang hak atas tanah, satuan rumah susun dan hak-hak lain yang terdaftar agar dengan mudah dapat membuktikan dirinya sebagai pemegang hak yang bersangkutan. Untuk memberikan kepastian hukum dan perlindungan hukum, kepada pemegang hak yang bersangkutan diberikan sertipikat hak atas tanah. Maka perlu adanya suatu kepastian hukum untuk menjamin keperluan rumah tinggal bagi Warga Negara Indonesia serta menjamin kelangsungan hak atas tanahnya.

\section{PERMASALAHAN}

1. Bagaimana pelaksanaan peningkatan Hak Guna Bangunan menjadi Hak Milik untuk Rumah Tinggal di Kantor ATR/BPN Kabupaten Karawang?

2. Apa syarat-syarat yang harus dipenuhi dalam proses peningkatan Hak Guna Bangunan menjadi Hak Milik di Kantor ATR/BPN Kabupaten Karawang?

\section{METODE PENELITIAN}

Permasalahan yang telah dirumuskan di atas akan dijawab atau 
PELAKSANAAN PENINGKATAN HAK GUNA BANGUNAN MENJADI HAK MILIK UNTUK RUMAH TINGGAL DI KANTOR PERTANAHAN KARAWANG DITINJAU DARI KEPUTUSAN MENTERI NEGARA AGRARIA / KEPALA BADAN PERTANAHAN NASIONAL NOMOR 6 TAHUN 1998 TENTANG PEMBERIAN HAK MILIK ATAS TANAH UNTUK RUMAH TINGGAL: Irma Garwan, Zarisnov Arafat, Yola Ardila

dipecahkan dengan menggunakan metode pendekatan yuridis empiris. Pendekatan yuridis (hukum dilihat sebagai norma atau das sollen), karena dalam membahas permasalahan penelitian ini menggunakan bahan-bahan hukum (baik hukum yang tertulis maupun hukum yang tidak tertulis atau baik bahan hukum primer maupun bahan hukum sekunder). Pendekatan empiris (hukum sebagai kenyataan sosial, kultural atau das sein), karena dalam penelitian ini digunakan data primer yang diperoleh dari lapangan.

Jadi, pendekatan yuridis empiris dalam penelitian ini maksudnya adalah bahwa dalam menganalisis permasalahan dilakukan dengan cara memadukan bahanbahan hukum (yang merupakan data sekunder) dengan data primer yang diperoleh di lapangan yaitu tentang pelaksanaan peningkatan hak guna bangunan menjadi hak milik untuk rumah tinggal.

\section{PEMBAHASAN}

\section{PELAKSANAAN PENINGKATAN \\ HAK GUNA BANGUNAN MENJADI HAK MILIK DI KANTOR ATR/BPN KABUPATEN KARAWANG}

Berdasarkan Pernyataan dari petugas kordinator peningkatan hak di Kantor ATR/BPN Kabupaten Karawang yaitu bapak Dadang Paryana yang mempunyai tugas untuk mencari berkas di buku tanah nomor Hak Guna Bangunannya, setelah di buku tanah ada maka akan di keluarkan nomor hak baru di aplikasi komputerisasi kantor pertanahan ( KKP ) Badan Pertanahan Nasional, kemudian di sertipikat dan buku tanah akan di coret nomor Hak Guna Bangunan yang lama dan akan di gantikan dengan nomor Hak Milik yang baru.

Legalitas kepemilikan tanah menjadi hal yang sangat penting dan perlu untuk dibuktikan, adapun kasus yang masih banyak terjadi adalah kepemilikan tanah yang masih berstatus Hak Guna Bangunan ( HGB ), tentunya masyarakat ingin memiliki status kepemilikan yang lebih kuat, untuk itu masyarakat perlu meningkatkannya menjadi sertipikat Hak Milik, perubahan status kepemilikan dari sertipikat Hak Guna Bangunan menjadi sertipikat Hak Milik ini memiliki tujuan guna memperjelas status hukum kepemilikannya, hal ini tentunya sangat bermanfaat bagi pemilik jika di kemudian 
PELAKSANAAN PENINGKATAN HAK GUNA BANGUNAN MENJADI HAK MILIK UNTUK RUMAH TINGGAL DI KANTOR PERTANAHAN KARAWANG DITINJAU DARI KEPUTUSAN MENTERI NEGARA AGRARIA / KEPALA BADAN PERTANAHAN NASIONAL NOMOR 6 TAHUN 1998 TENTANG PEMBERIAN HAK MILIK ATAS TANAH UNTUK RUMAH TINGGAL: Irma Garwan, Zarisnov Arafat, Yola Ardila

hari terjadi pindah tangan kepemilikan ataupun terjadi sengketa.

Untuk mengetahui proses peningkatan Hak Guna Bangunan menjadi Hak Milik untuk rumah tinggal harus memperhatikan hal-hal sebagai berikut :

a.Pemohon harus mengisi surat permohonan Hak Milik atas tanah untuk rumah tinggal di Kantor ATR/BPN Kabupaten Karawang yang diajukan secara tertulis kepada Kepala Kantor Pertanahan yang daerah kerjanya meliputi letak tanah yang bersangkutan, yaitu berupa lampiran yang bisa pemohon dapatkan di koperasi kantor ATR/BPK Kabupaten Karawang.

1)Lampiran 13 (terlampir)

2)Lampiran 1 berupa Keputusan Menteri Negara Agraria / Kepala Badan Pertanahan Nasional Nomor 6 Tahun 1998 tanggal 26 Juni 1998 Tentang Pemberian Hak Milik Atas Tanah Untuk Rumah Tinggal (terlampir)

3)Surat pernyataan (terlampir)

b.Pemohon juga harus melampirkan sertipikat tanah yang bersangkutan dalam permohonan peningkatan hak atas tanah dari Hak Guna Bangunan menjadi Hak Milik karena sertipikat tersebut dapat memberikan kepastian hukum kepada pemegang hak yang bersangkutan dan sebagai alat bukti yang sah dalam kepemilikannya, sertipikat tersebut harus sudah dilakukan pengecekan ke kantor ATR/BPN Kabupaten Karawang.

c.Bukti yang harus disertakan dalam penggunaan tanah untuk rumah tinggal berupa :

1)Mencantumkan foto copy Izin Mendirikan Bangunan (IMB) dari Instansi yang berwenang yang menerangkan bahwa bangunan tersebut telah digunakan untuk rumah tinggal, IMB tersebut diperlukan sebagai bukti legalitas.

2)Surat keterangan dari Kepala Desa atau Kelurahan letak tanah setempat yang menerangkan bahwa bangunan tersebut digunakan untuk rumah tinggal.

d.Permohonan harus disertai dengan melampirkan foto copy Surat Pemberitahuan Pajak Terhutang ( SPPT ) dan foto copy Pajak Bumi dan Bangunan ( PBB ) tahun terakhir.

e.Untuk pemberian Hak Milik atas tanah untuk rumah tinggal, identitas pemohon yang digunakan pemohon agar diperiksa 
PELAKSANAAN PENINGKATAN HAK GUNA BANGUNAN MENJADI HAK MILIK UNTUK RUMAH TINGGAL DI KANTOR PERTANAHAN KARAWANG DITINJAU DARI KEPUTUSAN MENTERI NEGARA AGRARIA / KEPALA BADAN PERTANAHAN NASIONAL NOMOR 6 TAHUN 1998 TENTANG PEMBERIAN HAK MILIK ATAS TANAH UNTUK RUMAH TINGGAL: Irma Garwan, Zarisnov Arafat, Yola Ardila

tentang kepemilikan tanah yang dimohonkan tersebut. Keterangan tersebut terdapat dalam sertipikat yang dimohonkan peningkatan haknya.

f.Adanya bukti perolehan hak atas tanah dan bangunan dimana bangunan tersebut berdiri. g.Setelah semua dokumen yang diperlukan sudah lengkap, maka dokumen diserahkan ke loket 9 ( Loket peningkatan hak) yaitu Ibu Ina Nur Oktaviani dimana petugas mempunyai fungsi untuk melakukan pemeriksaan dokumen yang diterima. Dokumen yang diperiksa adalah kelengkapan yang menjadi syarat dalam permohonan Hak Milik atas tanah untuk rumah tinggal.

h.Setelah berkas selesai di periksa oleh petugas loket 9 dan berkas tersebut sudah lengkap langsung di daftarkan untuk proses perubahan hak yang kemudian apabila sudah di daftarkan akan dikeluarkan surat perintah setor ( SPS ) dan tanda terima dokumen.

i.Setelah SPS keluar, maka pemohon di wajibkan untuk membayar Penerimaan Negara Bukan Pajak ( PNBP ) sebesar Rp.50.000, dapat dibayarkan melalui bank.
j.Apabila PNBP sudah dibayarkan maka pemohon harus memberikan bukti setor kepada petugas loket 9 .

k. Setelah berkas selesai di pengurusan loket maka berkas tersebut akan di naikkan ke kordinator perubahan hak yaitu Bapak Dadang Paryana untuk di cari di buku tanah nomor Hak Guna Bangunannya, setelah di buku tanah ada maka akan di keluarkan nomor hak baru di aplikasi komputerisasi kantor pertanahan ( KKP ) Badan Pertanahan Nasional.

1.Kemudian di sertipikat dan buku tanah, maka akan di coret nomor Hak Guna Bangunan yang lama dan akan di gantikan dengan nomor Hak Milik yang baru.

m.Setelah proses tersebut selesai maka berkas akan di naikkan ke Kepala Sub Seksi Pemeliharaan Data dan Pembinaan Pejabat Pembuat Akta Tanah ( PPAT ) yaitu Bapak Dadang Suratman Sumarna untuk dibubuhi paraf, yang mana menurut Pasal 16 Peraturan Menteri Agraria dan Tata Ruang / Kepala Badan Pertanahan Nasional Republik Indonesia Nomor 38 Tahun 2016 Tentang Organisasi dan Tata Kerja Kantor Wilayah Badan Pertanahan Nasional dan Kantor Pertanahan, seksi pemeliharaan data hak tanah dan pembinaan Pejabat Pembuat 
PELAKSANAAN PENINGKATAN HAK GUNA BANGUNAN MENJADI HAK MILIK UNTUK RUMAH TINGGAL DI KANTOR PERTANAHAN KARAWANG DITINJAU DARI KEPUTUSAN MENTERI NEGARA AGRARIA / KEPALA BADAN PERTANAHAN NASIONAL NOMOR 6 TAHUN 1998 TENTANG PEMBERIAN HAK MILIK ATAS TANAH UNTUK RUMAH TINGGAL: Irma Garwan, Zarisnov Arafat, Yola Ardila

Akta Tanah ( PPAT ) mempunyai tugas melakukan penyiapan bahan bimbingan teknis, koordinasi, pemantauan, pemeliharaan data pendaftaran tanah dan ruang, hak milik atas satuan rumah susun, hak pengelolaan, tanah wakaf, dan pemberian izin peralihan hak, pelepasan hak, perubahan penggunaan dan perubahan pemanfaatan/komoditas, peralihan saham, pengembangan dan pembinaan Pejabat Pembuat Akta Tanah ( PPAT ), pelaksanaan dan pengelolaan informasi dan Komputerisasi Kegiatan Pertanahan berbasis data yuridis, serta evaluasi dan pelaporan. ${ }^{13}$

n.Setelah proses paraf selesai berkas tersebut kemudian akan di naikkan ke Kepala Seksi Hubungan Hukum Pertanahan untuk ditanda tangan dan di cap oleh Bapak Soleh Hendrawan, SH yang mana menurut Pasal 13 Peraturan Menteri Agraria dan Tata Ruang / Kepala Badan Pertanahan Nasional Republik Indonesia Nomor 38 Tahun 2016 Tentang Organisasi dan Tata Kerja Kantor Wilayah Badan Pertanahan

13 Pasal 13 Peraturan Menteri Agraria dan Tata Ruang / Kepala Badan Pertanahan Nasional Republik Indonesia Nomor 38 Tahun 2016 Tentang Organisasi dan Tata Kerja Kantor Wilayah Badan Pertanahan Nasional dan Kantor Pertanahan
Nasional dan Kantor Pertanahan, bidang hubungan hukum pertanahan mempunyai fungsi melaksanakan pengoordinasian, pembinaan, dan pelaksanaan penetapan hak tanah dan pemberdayaan hak tanah masyarakat, pendaftaran hak tanah, dan pemeliharaan data hak tanah serta pembinaan Pejabat Pembuat Akta Tanah (PPAT). ${ }^{14}$ Pasal 14 Peraturan Menteri Agraria dan Tata Ruang / Kepala Badan Pertanahan Nasional Republik Indonesia Nomor 38 Tahun 2016 Tentang Organisasi dan Tata Kerja Kantor Wilayah Badan Pertanahan Nasional dan Kantor Pertanahan dalam melaksanakan tugas sebagaimana dimaksud Pasal 13, Bidang Hubungan Hukum Pertanahan menyelenggarakan fungsi :

1)Pelaksanaan pemberian penetapan, perpanjangan, dan penetapan kembali hak perseorangan dan badan hukum swasta, serta hak atas ruang dan hak komunal;

2)Penyiapan bahan pemberian izin dan penetapan hak atas tanah badan

\footnotetext{
14 Pasal 13 Peraturan Menteri Agraria dan Tata Ruang / Kepala Badan Pertanahan Nasional Republik Indonesia Nomor 38 Tahun 2016 Tentang Organisasi dan Tata Kerja Kantor Wilayah Badan Pertanahan Nasional dan Kantor Pertanahan
} 
PELAKSANAAN PENINGKATAN HAK GUNA BANGUNAN MENJADI HAK MILIK UNTUK RUMAH TINGGAL DI KANTOR PERTANAHAN KARAWANG DITINJAU DARI KEPUTUSAN MENTERI NEGARA AGRARIA / KEPALA BADAN PERTANAHAN NASIONAL NOMOR 6 TAHUN 1998 TENTANG PEMBERIAN HAK MILIK ATAS TANAH UNTUK RUMAH TINGGAL: Irma Garwan, Zarisnov Arafat, Yola Ardila

sosial/keagamaan serta penegasan sebagai tanah wakaf, tanah bekas milik Belanda, dan bekas tanah asing lainnya;

3)Penyiapan bahan penunjukan badan hukum tertentu yang dapat mempunyai hak milik;

4)Pelaksanaan inventarisasi dan identifikasi tanah hak perseorangan dan badan hukum swasta, serta hak atas ruang;

5)Pelaksanaan pemberdayaan hak atas tanah masyarakat;

6)Penyiapan kerjasama dengan lembaga pemerintah dan lembaga non pemerintah dalam rangka pemberdayaan hak atas tanah masyarakat;

7)Pelaksanaan pengembangan dan diseminasi model pemberdayaan hak atas tanah masyarakat;

8)Pelaksanaan pendaftaran hak atas tanah, hak atas ruang, hak milik atas satuan rumah susun, hak pengelolaan, hak tanggungan, tanah wakaf, hak atas tanah badan social / keagamaan dan pencatatan pembatalan hak serta hapusnya hak;
9)Pemeliharaan data pendaftaran tanah dan ruang, hak milik atas satuan rumah susun, hak pengelolaan,tanah wakaf, dan pemberian izin peralihan hak, pelepasan hak, perubahan penggunaan dan perubahan pemanfaatan / komoditas, peralihan saham, pengembangan dan pembinaan Pejabat Pembuat Akta Tanah ( PPAT);

10)Pelaksanaan dan pengelolaan informasi dan Komputerisasi Kegiatan Pertanahan berbasis data yuridis; dan

11)Pelaksanaan bimbingan teknis, koordinasi, pemantauan, evaluasi, dan pelaporan di bidang hubungan hukum pertanahan.

o.Apabila semua proses sudah selesai maka akan di cetak Nomor 301A, 307, 208 yaitu tanda terima untuk penyerahan berkas dan berkas tersebut selanjutnya akan di serahkan ke petugas loket penyerahan.

p.Pemohon dapat mengambil kembali berkas yang sudah selesai paling lama 5 hari kerja dengan membawa tanda terima dokumen untuk di serahkan pada petugas loket tersebut. 
PELAKSANAAN PENINGKATAN HAK GUNA BANGUNAN MENJADI HAK MILIK UNTUK RUMAH TINGGAL DI KANTOR PERTANAHAN KARAWANG DITINJAU DARI KEPUTUSAN MENTERI NEGARA AGRARIA / KEPALA BADAN PERTANAHAN NASIONAL NOMOR 6 TAHUN 1998 TENTANG PEMBERIAN HAK MILIK ATAS TANAH UNTUK RUMAH TINGGAL: Irma Garwan, Zarisnov Arafat, Yola Ardila

Berdasarkan Keputusan Menteri Negara Agraria / Kepala Badan Pertanahan Nasional Nomor 6 Tahun 1998 Tentang Pemberian Hak Milik atas tanah untuk rumah tinggal bahwa dalam proses pelaksanaan peningkatan Hak Guna Bangunan menjadi Hak Milik adalah sebagai berikut :

1.Hak Guna Bangunan atau Hak Pakai atas tanah untuk rumah tinggal kepunyaan perseorangan Warga Negara Indonesia yang luasnya 600 M2 atau kurang, atas permohonan yang bersangkutan dihapus dan diberikan kembali kepada bekas pemegang haknya dengan Hak Milik; 2.Tanah Hak Guna Bangunan atau Hak Pakai atas tanah untuk rumah tinggal kepunyaan perseorangan Warga Negara Indonesia yang luasnya 600 M2 atau kurang yang sudah habis jangka waktunya dan masih dipunyai oleh bekas pemegang hak tersebut, atas permohonan yang bersangkutan diberikan Hak Milik kepada bekas pemegang hak.

Untuk pemberian Hak Milik terebut penerima hak harus membayar uang pemasukan kepada Negara sesuai ketentuan yang berlaku. Permohonan Pendaftaran Hak Milik diajukan kepada Kantor Pertanahan Kabupaten / Kotamadya setempat dengan surat sesuai bentuk sebagaimana contoh dalam Lampiran I Keputusan ini dengan disertai :

1.Sertipikat tanah yang bersangkutan

2.Bukti penggunaan tanah untuk rumah tinggal berupa :

a.Fotocopy Izin Mendirikan Bangunan （IMB ） yang mencantumkan bahwa bangunan tersebut digunakan untuk rumah tinggal, atau

b.Surat keterangan dari Kepala Desa/Kelurahan setempatbahwa bangunan tersebut digunakan untuk rumah tinggal, apabila izin mendirikan bangunan tersebut belum dikeluarkan oleh instansi berwenang

3.Fotocopy SPPT PBB yang terakhir ( khusus untuk tanah yang luasnya 200 M2 atau lebih ).

4.Bukti identitas pemohon.

5.Pernyataan dari pemohon bahwa dengan perolehan Hak Milik yang dimohon pendaftarannya itu yang bersangkutan akan 
PELAKSANAAN PENINGKATAN HAK GUNA BANGUNAN MENJADI HAK MILIK UNTUK RUMAH TINGGAL DI KANTOR PERTANAHAN KARAWANG DITINJAU DARI KEPUTUSAN MENTERI NEGARA AGRARIA / KEPALA BADAN PERTANAHAN NASIONAL NOMOR 6 TAHUN 1998 TENTANG PEMBERIAN HAK MILIK ATAS TANAH UNTUK RUMAH TINGGAL: Irma Garwan, Zarisnov Arafat, Yola Ardila

mempunyai Hak Milik atas tanah untuk rumah tinggal tidak lebih dari 5 (lima) bidang yang seluruhnya meliputi luas tanah tidak lebih dari 5000 M2 dengan menggunakan contoh sebagaimana Lampiran II Keputusan ini.

Atas permohonan pendaftaran Hak Milik sebagaimana dimaksud Ayat (1) Keputusan Menteri Negara Agraria / Kepala Badan Pertanahan Nasional Nomor 6 Tahun 1998 Tentang Pemberian Hak Milik atas tanah untuk rumah tingggal bahwa kepala Kantor Pertanahan mengeluarkan perintah setor pungutan sebagaimana dimaksud dalam Pasal 1 Ayat (2) yang dibuat sesuai contoh sebagaimana Lampiran III Keputusan ini. Setelah pungutan sebagaimana dimaksud Ayat (2) dibayar luas, Kepala Kantor Pertanahan Kabupaten/Kotamadya mendaftar hapusnya Hak Guna Bangunan atau Hak Pakai yang bersangkutan dalam buku tanah dan sertipikatnya serta daftar umum lainnya, selanjutnya mendaftar Hak Milik atas tanah berkas Hak Guna Bangunan atau Hak Pakai tersebut dengan membuat buku tanahnya dengan menyebutkan keputusan ini sebagai dasarnya adanya Hak Milik tersebut dan menerbitkan sertipikatnya, dengan surat ukur yang dibuat berdasarkan data fisik yang digunakan dalam pendaftaran Hak Guna Bangunan atau Hak Pakai.

Pernyataan yang dinyatakan oleh petugas peningkatan Hak dengan Keputusan Menteri Negara Agraria / Kepala Badan Pertanahan Nasional Nomor 6 Tahun 1998 Tentang Pemberian Hak Milik atas tanah untuk rumah tinggal dalam proses pelaksanaanya sudah sesuai dengan aturan yang berlaku dan tidak ada ketimpangan.

Untuk biaya yang harus dibayar oleh pemohon dalam mengajukan Peningkatan Hak Guna Bangunan menjadi Hak Milik untuk rumah tinggal adalah sebagai berikut : 1.Untuk pemberian Hak Milik dengan Keputusan ini harus dibayar uang pemasukan kepada Negara yang ditetapkan berdasarkan ketentuan yang berlaku, yaitu Peraturan Menteri Negara Agraria / Kepala Badan Pertanahan Nasional Nomor 4 Tahun 1998 Tentang Pedoman Penetapan Uang Pemasukan.

2.Nilai Jual Objek Pajak ( NJOP ) yang digunakan dalam menghitung uang pemasukan tersebut adalah Nilai Jual Objek Pajak ( NJOP ) pada tanggal permohonan pendaftaran, yang dapat diketahui dari Surat Pemberitahuan Pajak Terhutang Pajak 
PELAKSANAAN PENINGKATAN HAK GUNA BANGUNAN MENJADI HAK MILIK UNTUK RUMAH TINGGAL DI KANTOR PERTANAHAN KARAWANG DITINJAU DARI KEPUTUSAN MENTERI NEGARA AGRARIA / KEPALA BADAN PERTANAHAN NASIONAL NOMOR 6 TAHUN 1998 TENTANG PEMBERIAN HAK MILIK ATAS TANAH UNTUK RUMAH TINGGAL: Irma Garwan, Zarisnov Arafat, Yola Ardila

Bumi dan Bangunan ( SPPT PBB ) yang copynya disertakan pada permohonan pendaftaran Hak Milik atas tanah yaitu bidang tanah yang uang pemasukannya ditetapkan lebih dari pada $0 \%$. Untuk keperluan ini diberikan ketentuan sebagai berikut :

a.Permohonan pendaftaran Hak Milik yang disampaikan sesudah tanggal perhitungan uang pemasukannya dilakukan berdasarkan NJOP yang tercantum dalam SPPT PBB tahun yang bersangkutan.

b.Permohonan pendaftaran Hak Milik yang disampaikan sebelum tanggal perhitungan uang pemasukannya dilakukan berdasarkan NJOP yang tercantum dalam SPPT PBB tahun sebelumnya. c.Untuk pendaftaran Hak Milik ini harus dibayar biaya pembuatan sertipikat menurut Peraturan Kepala Badan Pertanahan Nasional Nomor 2 Tahun 1992 Tentang biaya pendaftaran tanah. Oleh karena itu pemberian Hak Milik dengan keputusan ini merupakan perubahan hak dari Hak Guna Bangunan ( baik yang masih berlaku maupun yang sudah habis jangka waktunya ) dan tidak ada perubahan nama pemegangnya, maka atas perolehan Hak Milik itu tidak dikenakan Bea Perolehan Hak Atas Tanah dan Bangunan.

\section{SYARAT-SYARAT YANG HARUS DIPENUHI DALAM PELAKSANAAN PENINGKATAN HAK GUNA BANGUNAN MENJADI HAK MILIK UNTUK RUMAH TINGGAL DI KANTOR ATR/BPN KARAWANG}

Pada saat ini masih banyak masyarakat yang belum mengetahui dalam memenuhi syarat-syarat yang harus dipenuhi dan ditetapkan untuk melaksanakan peningkatan hak atas tanah di kantor ATR/BPN Kabuapten Karawang, adalah sebagai berikut :

a.Foto copy Kartu Tanda Penduduk (KTP) sebagai identitas pemohon sesuai dengan nama pemilik sertipikat di Hak Guna Bangunan

b.Foto copy Kartu Keluarga (KK) pemohon 
PELAKSANAAN PENINGKATAN HAK GUNA BANGUNAN MENJADI HAK MILIK UNTUK RUMAH TINGGAL DI KANTOR PERTANAHAN KARAWANG DITINJAU DARI KEPUTUSAN MENTERI NEGARA AGRARIA / KEPALA BADAN PERTANAHAN NASIONAL NOMOR 6 TAHUN 1998 TENTANG PEMBERIAN HAK MILIK ATAS TANAH UNTUK RUMAH TINGGAL: Irma Garwan, Zarisnov Arafat, Yola Ardila

c.Foto copy Surat Pemberitahuan Pajak

Terhutang Pajak Bumi dan Bangunan (SPPT PBB) tahun terakhir

d.Foto copy Izin Mendirikan Bangunan (IMB)

e.Sertipikat asli Hak Guna Bangunan

f.Mengisi formulir peningkatan hak

Persyaratan-persyaratan tersebut

yang harus dipenuhi oleh pemohon untuk meningkatkan Hak Guna Bangunannya menjadi Hak Milik di Kantor ATR/BPN Kabupaten Karawang.

Dasar hukum peningkatan Hak Guna Bangunan menjadi Hak Milik adalah Keputusan Menteri Negara Agraria / Kepala Badan Pertanahan Nasional Nomor 6 Tahun 1998 yang merupakan penetapan pemerintah yang ditentukan didalam Pasal 22 Ayat (2) huruf a Undang-Undang Nomor 5 Tahun 1960 Tentang Peraturan Dasar Pokok-Pokok Agraria yang menyangkut pemberian Hak Milik yang sebelumnya hak tersebut Hak Guna Bangunan. Pasal 22 Ayat (2) Undang-Undang Nomor 5 Tahun 1960 Tentang Peraturan Dasar PokokPokok Agraria menyatakan :

Selain menurut cara sebagai yang dimaksud dalam Ayat (1) Pasal ini hak milik terjadi karena :
a.Penetapan Pemerintah menurut cara dan syarat-syarat yang ditetapkan dengan peraturan pemerintah

b.Ketentuan Undang-Undang ${ }^{15}$

Yang dimaksud dengan penetapan pemerintah dalam kaitannya dengan perolehan hak atas tanah adalah suatu keputusan yang diterbitkan oleh pejabat yang berwenang untuk membrikan hak atas tanah. Pejabat yang berwenang ini adalah Kementrian Agraria dan Tata Ruang / Kepala Badan Pertanahan Nasional atau Kepala Kantor Wilayah Agraria dan Tata Ruang / Kepala Badan Pertanahan Nasional Provinsi atau Kepala Kantor Pertanahan Kabupaten/Kota yang diberikan pelimpahan wewenang untuk memberikan hak atas tanah. Ketentuan hukum ini dikeluarkan dengan tujuan untuk memberikan kemudahan bagi masyarakat untuk memiliki rumah tinggal dengan status Hak Milik.

Penerimaan Negara Bukan Pajak ( PNBP ) yang wajib dibayarkan oleh pemohon dalam peningkatan Hak Guna Bangunan menjadi Hak Milik diatur dalam

15 Pasal 22 Ayat (2) Undang-Undang Nomor 5 Tahun 1960 Tentang Peraturan Dasar PokokPokok Agraria 
PELAKSANAAN PENINGKATAN HAK GUNA BANGUNAN MENJADI HAK MILIK UNTUK RUMAH TINGGAL DI KANTOR PERTANAHAN KARAWANG DITINJAU DARI KEPUTUSAN MENTERI NEGARA AGRARIA / KEPALA BADAN PERTANAHAN NASIONAL NOMOR 6 TAHUN 1998 TENTANG PEMBERIAN HAK MILIK ATAS TANAH UNTUK RUMAH TINGGAL: Irma Garwan, Zarisnov Arafat, Yola Ardila

Lampiran Peraturan Pemerintah Nomor 128

Tahun 2015 Tentang Jenis dan Tarif atas Jenis Penerimaan Negara Bukan Pajak yang berlaku pada Kementrian Agraria dan Tata Ruang / Badan Pertanahan Nasional adalah sebesar Rp.50.000,-/bidang. Dalam praktiknya jika dikuasakan melalui pihak ketiga akan ada biaya tambahan jasa, sehingga untuk menekan biaya, sebaiknya pemilik sertipikat mengurus sendiri proses peningkatan status tersebut ke Kantor Pertanahan Karawang. Pihak ketiga yang dikuasakan untuk mengurus peningkatan Hak Guna Bangunan menjadi Hak Milik pada umumnya adalah Notaris dan/atau Pejabat Pembuat Akta Tanah (yang selanjutnya disebut PPAT). Dengan dikuasakan kepada Notaris dan/atau PPAT, maka pemohon hanya tinggal tunggu selesai tanpa perlu datang langsung ke Kantor Pertanahan Karawang.

Dalam proses peningkatan Hak Guna Bangunan menjadi Hak Milik terdapat syarat-syarat yang harus di penuhi oleh pemohon kepada Kantor ATR/BPN Kabupaten Karawang saat jangka waktu Hak Guna Bangunan belum berakhir dan/atau yang sudah berakhir. Persyaratan yang harus dipenuhi untuk melakukan peningkatan Hak Guna Bangunan menjadi Hak Milik saat jangka waktu Hak Guna Bangunan belum berakhir dan/atau sudah berakhir adalah :

a.Foto copy Kartu Tanda Penduduk ( KTP ) Pemohon, sesuai dengan nama yang tertera di sertipikat;

b.Sertipikat asli Hak Guna Bangunan;

c.Foto copy Surat Pemberitahuan Pajak Terhutang Pajak Buni dan Bangunan ( SPPT PBB ) tahun berjalan;

d.Foto copy Izin Mendirikan Bangunan ( IMB ) / Surat Keterangan Kelurahan yang menyatakan bahwa bangunan tersebut benar digunakan untuk rumah tinggal;

e.Surat pernyataan tanah tidak melibihi lima bidang tanah yang seluruhnya mencapai luas tidak lebih dari 5000 M2 (lima ribu meter persegi);

f.Surat Kuasa Pengurusan (apabila pengurusannya dilakukan oleh pihak ketiga); Persyaratan-persyaratan di atas berdasarkan Pasal 2 Ayat (1) Keputusan Menteri Negara Agraria / Kepala Badan Pertanahan Nasional Nomor 6 Tahun 1998 Tentang Pemberian Hak Milik atas tanah untuk rumah tinggal, menyatakan :

Permohonan pendaftaran Hak Milik sebagaimana dimaksud Pasal 1 diajukan 
PELAKSANAAN PENINGKATAN HAK GUNA BANGUNAN MENJADI HAK MILIK UNTUK RUMAH TINGGAL DI KANTOR PERTANAHAN KARAWANG DITINJAU DARI KEPUTUSAN MENTERI NEGARA AGRARIA / KEPALA BADAN PERTANAHAN NASIONAL NOMOR 6 TAHUN 1998 TENTANG PEMBERIAN HAK MILIK ATAS TANAH UNTUK RUMAH TINGGAL: Irma Garwan, Zarisnov Arafat, Yola Ardila

kepada Kepala Kantor Pertanahan Kabupaten / Kotamadya setempat dengan surat sesuai bentuk sebagaimana contoh dalam Lampiran I Keputusan ini dengan disertai :

a.Sertipikat tanah yang bersangkutan;

b.Bukti penggunaan tanah untuk rumah tinggal berupa:

1)Foto copy Izin Mendirikan Bangunan ( IMB ) yang mencantumkan bahwa banguna tersebut digunakan untuk rumah tinggal, atau

2)Surat keterangan dari Kepala Desa / Kelurahan setempat bahwa bangunan tersebut digunakan untuk rumah tingga, apabila Izin Mendirikan Bangunan tersebut belum dikeluarkan oleh instansi berwenang. c.Foto copy SPPT PBB yang terakhir (khusus untuk tanah yang luasnya $200 \mathrm{~m} 2$ atau lebih);

d.Bukti identitas pemohon;

e.Pernyataan dari pemohon bahwa dengan perolehan Hak Milik yang dimohonkan pendaftarannya itu yang bersangkutan akan mempunyai Hak Milik atas tanah untuk rumah tinggal tidak lebih dari 5 (lima) bidang tanah yang seluruhnya meliputi luas tidak lebih dari $5000 \mathrm{~m} 2$ (lima ribu meter persegi) dengan menggunakan contoh sebagaimana Lampiran II Keputusan ini. ${ }^{16}$

Atas permohonan pendaftaran Hak Milik sebagaimana dimaksud Ayat (1) Kepala kantor Pertanahan mengeluarkan perintah setor pungutan sebagaimana dimaksud dalam Pasal 1 Ayat (2) yang dibuat sesuai contoh sebagaimana lampiran III Keputusan ini.

Berdasarkan pernyataan dari petugas peningkatan hak dengan Keputusan Menteri Negara Agraria/Kepala Badan Pertanahan Nasional Nomor 6 Tahun 1998 Tentang Pemberian Hak Milik atas tanah untuk rumah tinggal, bahwa dalam persyaratan yang harus dipenuhi dalam pelaksanaan peningkatan hak yaitu sudah sesuai dengan aturan yang berlaku.

Untuk dapat mengajukan permohonan Hak Milik atas tanah untuk rumah tinggal, maka pemohon harus mengetahui terlebuh dahulu pembatasan pemberian Hak Milik untuk rumah tinggal. Adapun pembatasan Hak Milik tersebut adalah :

\footnotetext{
${ }^{16}$ Pasal 2 Ayat (1) Keputusan Menteri Negara Agraria / Kepala Badan Pertanahan Nasional Nomor 6 Tahun 1998 Tentang Pemberian Hak Milik atas tanah untuk rumah tinggal
} 
PELAKSANAAN PENINGKATAN HAK GUNA BANGUNAN MENJADI HAK MILIK UNTUK RUMAH TINGGAL DI KANTOR PERTANAHAN KARAWANG DITINJAU DARI KEPUTUSAN MENTERI NEGARA AGRARIA / KEPALA BADAN PERTANAHAN NASIONAL NOMOR 6 TAHUN 1998 TENTANG PEMBERIAN HAK MILIK ATAS TANAH UNTUK RUMAH TINGGAL: Irma Garwan, Zarisnov Arafat, Yola Ardila

1.Untuk setiap bidang tanah yang dimohonkan, luasnya tidak boleh lebih dari 2000 M2. Dalam Pasal 4 Ayat 2 Keputusan Menteri Negara Agraria / Kepala Badan Pertanahan Nasional Nomor 6 Tahun 1998 Tentang Pemberian Hak Milik atas tanah untuk rumah tinggal ditetapkan pembatasan permohonan Hak Milik atas tanah Negara, yaitu tidak lebih dari 2000 M2. Pembatasan ini hanya berlaku untuk permohonan Hak Milik untuk tanah yang seluruhnya atau utamanya dipergunakan untuk rumah tinggal, dan tidak berlaku untuk pemberian Hak Milik di daerah pedesaan yang penggunaan tanahnya selain untuk rumah tinggal juga untuk pekarangan atau kebun.

2.Setiap pemohon dibatasi pemilikan Hak Milik atas tanah untuk rumah tinggal tidak boleh dari 5 ( lima ) bidang. Untuk itu, permohonan Hak Milik yang bersangkutan akan mempunyai Hak Milik atas tanah untuk rumah tinggal tidak lebih dari 5 ( lima ) bidang dan seluruhnya meliputi luas tidak boleh lebih dari $5000 \mathrm{M} 2$.

Pernyataan ini berfungsi sebagai pemberian keterangan resmi dari pemohon yang akan mempunyai akibat hukum apabila dikemudian hari ternyata keterangan itu tidak benar atau palsu.

Dalam pelaksanaan pembatasan untuk pemberian Hak Milik atas tanah untuk rumah tinggal di Kantor Pertanahan Karawang mengacu pada Keputusan Menteri Negara Agraria / Kepala Badan Pertanahan Nasional Nomor 6 Tahun 1998 Tentang Pemberian Hak Milik atas tanah untuk rumah tinggal. Dalam Pasal 4 Ayat ( 2 ) mengenai permohonan Hak Milik atas tanah untuk rumah tinggal dibata si tanah seluas 2000 M2, dan dalam Pasal 4 Ayat ( 3 ) tentang pernyataan tanah untuk rumah tinggal tidak boleh lebih dari 5 ( lima ) bidang yang meliputi luasnya tidak lebih dari $5000 \mathrm{M} 2$..

\section{KESIMPULAN}

1.Dalam proses pelaksanaan peningkatan Hak Guna Bangunan menjadi Hak Milik di Kantor ATR/BPN Kabupaten Karawang dengan Keputusan Menteri Negara Agraria / Kepala Badan Pertanahan Nasional Nomor 
PELAKSANAAN PENINGKATAN HAK GUNA BANGUNAN MENJADI HAK MILIK UNTUK RUMAH TINGGAL DI KANTOR PERTANAHAN KARAWANG DITINJAU DARI KEPUTUSAN MENTERI NEGARA AGRARIA / KEPALA BADAN PERTANAHAN NASIONAL NOMOR 6 TAHUN 1998 TENTANG PEMBERIAN HAK MILIK ATAS TANAH UNTUK RUMAH TINGGAL: Irma Garwan, Zarisnov Arafat, Yola Ardila

6 Tahun 1998 Tentang Pemberian Hak Milik atas tanah untuk rumah tinggal sudah sesuai, yang pertama harus dilakukan oleh pemohon yaitu mendaftarkan hak nya ke loket 9 bagian peningkatan hak dengan membawa persyaratan yang sudah lengkap dan membayar surat perintah setor ( SPS ) selanjutnya proses yang dilakukanan pencoretan nomor hak lama dan di gantikan dengan nomor hak baru oleh petugas kordinator peningkatan hak untuk proses selanjutnya di berikan paraf, tanda tangan dan diberi cap oleh pejabat yang berwenang. Pembatasan pemberian Hak Milik atas tanah yang dimohon untuk rumah tinggal untuk setiap bidang tanah yang dimohonkan luasnya tidak boleh lebih dari 2000 M2 ( dua ribu meter persegi ). Setiap pemohon dibatasi pemilikan Hak Milik atas tanah untuk rumah tinggal tidak lebih dari 5 ( lima ) bidang tanah yang luas keseluruhannya 5000 M2 (lima ribu meter persegi) , untuk biaya yang harus dikeluarkan oleh pemohon dalam peningkatan Hak Guna Bangunan menjadi Hak Milik adalah sebesar Rp.50.000,- ( lima puluh ribu rupiah ) perbidang.

2.Pada saat ini masih banyak masyarakat yang belum mengetahui apa saja syarat- syarat yang harus dipenuhi dalam proses peningkatan Hak Guna Bangunan menjadi Hak Milik di Kantor ATR/BPN Kabupaten Karawang sehingga menunda pelaksanaan peningkatan hak tersebut dikarenakan berkas yang tidak lengkap, berikut syaratsyarat yang harus dilengkapi yaitu:

a.Foto copy Kartu Tanda Penduduk ( KTP) sesuai dengan nama di sertipikat Hak Guna Bangunan b.Foto copy Kartu Keluarga c.Foto copy SPPT PBB tahun terakhir

d.Foto copy Izin Mendirikan Bangunan ( IMB )

e.Sertipikat asli Hak Guna Bangunan

f.Mengisi formulir peningkatan hak.

\section{SARAN}

1.Meningkatkan Hak Guna Bangunan menjadi Hak Milik sebenarnya sangat diharuskan karena Hak Milik mempunyai kekuatan hukum yang lebih tinggi dari pada Hak Guna Bangunan dan Hak Milik tidak memiliki jangka waktu kepemilikiannya, namun pada saat ini masih banyak masyarakat yang belum meningkatkan hak atas tanahnya, karena disebabkan ada 
PELAKSANAAN PENINGKATAN HAK GUNA BANGUNAN MENJADI HAK MILIK UNTUK RUMAH TINGGAL DI KANTOR PERTANAHAN KARAWANG DITINJAU DARI KEPUTUSAN MENTERI NEGARA AGRARIA / KEPALA BADAN PERTANAHAN NASIONAL NOMOR 6 TAHUN 1998 TENTANG PEMBERIAN HAK MILIK ATAS TANAH UNTUK RUMAH TINGGAL: Irma Garwan, Zarisnov Arafat, Yola Ardila

beberapa kendala-kendala yang dihadapi masyarakat bahwa masyarakat belum semuanya mengetahui syarat-syarat yang harus dipenuhi dalam peningkatan hak tersebut..

2.Alangkah baiknya dari pihak Kantor ATR/BPN Kabupaten Karawang memberikan sosialisasi kepada masyarakat agar masyarakat lebih mengetahui syaratsyarat apa saja yang harus dipenuhi apabila ingin meningkatkan hak nya ke Kantor ATR/BPN Kabupaten Karawang.

\section{DAFTAR PUSTAKA}

\section{A.Buku}

Bernhard limbong, Hukum Agraria Nasional, Pustaka Margaretha, Jakarta, 2012.

R.Subekti, Tjitrosudibio.R, Kitab UndangUndang Hukum Perdata, Balai Pustaka, 2014.

Supriadi, Hukum Agraria, Sinar Grafika, Jakarta, 2015.

Waskito dan Hadi Arnowo, Pertanahan, Agraria, dan Tata Ruang, Kencana Pranadamedia Group, Jakarta, 2017.

\author{
Undang-Undang Nomor 5 Tahun 1960 \\ Tentang Peraturan Dasar Pokok- \\ Pokok Agraria. \\ Peraturan Pemerintah Republik Indonesia \\ Nomor 40 Tahun 1996 Tentang \\ Hak Guna Usaha, Hak Guna \\ Bangunan dan Hak Pakai Atas \\ Tanah.
}

Keputusan Menteri Negara Agraria / Kepala Badan Pertanahan Nasional Nomor 6 Tahun 1998 Tentang Pemberian Hak Milik Atas Tanah Untuk Rumah Tinggal.

\section{C.Sumber Lainnya}

https://www.lamudi.co.id/journal/perbedaan -hak-guna-bangunan-dengan-hakmilik/

\section{B.Perundang-Undangan}

